\title{
Türkiye mantar üretimi ve ARIMA (Box-Jenkins) ile projeksiyonu
}

\author{
Mushroom production and projection in Turkey using ARIMA (Box-Jenkins)
}

\author{
Rifat KURT ${ }^{1}$ \\ Selman KARAYILMAZLAR ${ }^{1}$
}

${ }^{1}$ Bartın Orman Fakültesi, Orman Endüstri Mühendisliği, Bartın

Sorumlu yazar (Corresponding author) Rifat KURT

rkurt@bartin.edu.tr

Geliş tarihi (Received)

19.09.2018

Kabul Tarihi (Accepted)

12.12.2018

Atıf (To cite this article): KURT, R, KARAYILMAZLAR, S . (2019). Türkiye mantar üretimi ve ARIMA (Box-Jenkins) ile projeksiyonu. Ormancılık Araștırma Dergisi, 6 (1), 72-76. DOI: https://doi.org/10.17568/ogmoad.461534

\section{$\ddot{O} z$}

Artan nüfus ile birlikte alternatif besin kaynaklarına olan gereksinim giderek önem kazanmıştır. Mantar, uygun şartların sağlanması durumunda yıl boyunca birden fazla ürün alınabilen, kolay yetiştirilebilen ve besin değeri yüksek bir ürün olmasının yanında, doğada mevsimine bağlı olarak kendiliğinden yetişebilen ve kırsal alanda yaşayan insanların besin ihtiyacını karşılayan önemli bir gıda maddesidir. Bu çalışmada, Türkiye'nin mantar üretimi incelenmiş ve Türkiye mantar üretiminin gelecekteki durumunu belirlemek amacıyla tahmin yapılmıştır. Bu kapsamda, 1985-2016 yılları arasındaki verilerden yola çıkarak gelecek on yıllık mantar üretim değerleri ARIMA (Box-Jenkins) yöntemi ile tahmin edilmiştir. Sonuçlar, Türkiye mantar üretiminin kademeli bir şekilde artarak 2025 yılında 100 bin tonu aşacağını göstermiştir.

Anahtar Kelimeler: Mantar, üretim, tahmin, ARIMA

\begin{abstract}
The need for alternative food sources has become more important with the rapid increase in population. Mushroom is an important food, which can be harvested more than once a year under suitable conditions, easily grown and is high in nutritional value. It can also grow spontaneously in nature depending on the season and meet the nutritional needs of people living in the rural areas. The purpose of this study was to examine the mushroom production in Turkey and estimations were made to determine mushroom production in Turkey in the future. In this context, using the data from 19852016, mushroom production values for the next ten years have been estimated using ARIMA (Box-Jenkins). The results showed that the mushroom production of Turkey would exceed 100 thousand tons in 2025 by gradually increasing.
\end{abstract}

Keywords: Mushroom, production, forecast, ARIMA

\section{Giriş}

Günümüzde mantarın insan beslenmesi ve sağlığı bakımından değerinin daha iyi anlaşılmasıly birlikte mantar yetiştiriciliğine olan merak ve ilgi son yıllarda hızlı bir şekilde artış göstermiştir (Kibar, 2015). Bu artış beraberinde yenilebilir mantar pazarında yüksek ticari potansiyel sağlamış ve bu ürünü önemli odun dışı orman ürünlerinden biri hâline getirmiştir (Boa, 2004).

Mantar üretimi için gerekli ham madde potansiyeli oldukça yüksek olan Türkiye'de, birçok endüstriyel ve tarımsal atığın mantar yetiştirmede kompost olarak kullanılması ve bunların teminindeki kolaylıklar üretimi cazip hâle getirmektedir (Erkel, 1992). Günümüzde kavak, meşe, çam, kayın, akçaağaç, huş gibi ağaç türlerinin 
talaşı, hububat samanı, mısır koçanı, çay artığ 1 , ayçiçeği tohum kabuğu, pamuk tohumu atıkları gibi çok sayıda tarımsal atık mantar yetiştiriciliğinde yetişme ortamı olarak kullanılabilmektedir (Şen ve Yalçın, 2010).

Toprak ve tarım arazisi gerektirmeden, kontrollü koşullarda, çevre şartlarına bağlı kalmadan bütün yıl boyunca üretilebilen ve besin değeri yüksek olan mantarlar, dünyada özellikle protein açığ olan ve gelişmekte olan ülkelerde besin ihtiyac1nı karşılayacak en etkili besin maddelerinden biri olarak görülmektedir (Kibar, 2015).

Dünya'da 2016 yılında 10 milyon tonun üzerinde mantar üretildiği belirtilmektedir. Sırasıyla Çin, İtalya, ABD, Hollanda ve Polonya en fazla mantar üretimi yapan ülkeler olarak karşımıza çıkmaktadir (Kurt vd., 2018a).

Türkiye'de ise ilk olarak 1960'lı yıllarda kültürü yapılmaya başlanan mantar, 1990'lı y1llardan itibaren ticari olarak değer kazanmış ve bu tarihten itibaren ticari bir sektör olarak gelişmeye başlamıştır (Eren ve Pekşen, 2014). 1973 yılında 80 ton olan Türkiye mantar üretimi zamanla artarak 2008 yılında 26 bin tona, 2016 yilinda ise 40,2 bin tona ulaşmıştır. 2016 yılında Türkiye'de en fazla kültür mantarı üretimi yapan iller sırasıyla Antalya, Burdur, Konya ve Kocaeli olmuştur (Kurt vd., 2018a; FAO, 2018; TÜİK, 2018).

Bu çalışmada, Türkiye'nin 1985-2016 yılları arasındaki mantar üretim verileri incelenmiş ve gelecek on yıllık mantar üretim değerleri ARIMA (Autoregressive Integrated Moving Average) yöntemi kullanılarak tahmin edilmiştir.

\section{Materyal ve Yöntem}

Çalışma materyalini Türkiye'nin 1985-2016 yıllarına ait 32 yıllık mantar üretim değerleri oluşturmaktadır (Tablo 1).

Çalışmada tahmin yöntemi olarak zaman serileri analiz tekniklerinden biri olan Otoregresif Hareketli Ortalama, yani yaygın olarak bilinen ismiyle ARIMA (Box-Jenkins) yöntemi kullanılmıştır. İstatistiki testlerin yapılmasında ve tahmin işleminin gerçekleştirilmesinde MINITAB paket programından yararlanılmıştır.

ARIMA modeli kurulup tahmin aşamasına geçmeden önce mantar üretim değerleri tahmin başarısını artırmak amacıyla ilk olarak logaritmik hâle getirilmiştir. Daha sonra modelin en önemli varsayımlarından biri olan durağanlık koşulunu sağlayıp sağlamadığı birim kök testlerinden biri olan Genelleştirilmiş Dickey-Fuller (ADF) testi ile sınan- mış ve veriler durağanlaştırıldıktan sonra tahmin aşamasına geçilmiştir.

Tablo 1. Türkiye mantar üretimi (FAO, 2018)

Table 1. Mushroom production in Turkey (FAO, 2018)

\begin{tabular}{crcc}
\hline Yillar & $\begin{array}{c}\text { Mantar üretimi } \\
\text { (Ton) }\end{array}$ & Y1llar & $\begin{array}{c}\text { Mantar üretimi } \\
\text { (Ton) }\end{array}$ \\
\hline 1985 & 200 & 2001 & 9.000 \\
1986 & 340 & 2002 & 11.000 \\
1987 & 4.400 & 2003 & 13.000 \\
1988 & 2.400 & 2004 & 15.000 \\
1989 & 1.000 & 2005 & 17.000 \\
1990 & 300 & 2006 & 21.833 \\
1991 & 1.300 & 2007 & 23.426 \\
1992 & 1.000 & 2008 & 26.526 \\
1993 & 1.066 & 2009 & 19.501 \\
1994 & 1.586 & 2010 & 21.559 \\
1995 & 2.276 & 2011 & 27.058 \\
1996 & 2.000 & 2012 & 33.750 \\
1997 & 1.200 & 2013 & 34.494 \\
1998 & 3.000 & 2014 & 38.767 \\
1999 & 5.000 & 2015 & 39.495 \\
2000 & 7.000 & 2016 & 40.272 \\
\hline
\end{tabular}

\subsection{ARIMA (Box-Jenkins) yöntemi ve ADF testi}

Zaman serileri uygulamalarının temelinde yatan varsayım, kullanılan verilerin durağan olmasıdır. Durağan kavram1, sürecin herhangi bir trend taŞımaması, zaman içinde ortalama ve varyansında bir değişme olmaması anlamına gelmektedir. Bu tip serilerde ARMA (p,q), ve bu modelin özel hâli olan AR(p) ve MA (q) modellerinden uygun olanı kullanılabilmektedir. Ancak gerçekte zaman serilerinin ortalama ve varyansında zamana bağlı değişmeler olabilmektedir. Bu durumda seri durağan hâle getirilerek tahmin işleminde kullanılabilir. Zaman serilerinin durağanlaştırılması işlemi ise serinin birinci ve ikinci farkları alınarak yapılmaktadir. Bu durumda model, ARIMA (p,d,q) olarak ifade edilmektedir (Hamzaçebi ve Kutay, 2004; Topçuoğlu vd., 2005; Özdemir ve Bahadır, 2010).

Box ve Jenkins'in (1970) zaman serisi analizi kitaplarında doğrusal stokastik modellerin bir ailesi olarak tanımladığı yöntem, günümüzde Box-Jenkins veya ARIMA olarak bilinmekte ve durağan olmayan ancak fark alma işlemiyle durağan hâle dönüştürülmüş serilere uygulanmaktadır (Kurt vd., 2018b).

Genel olarak ARIMA (p,d,q) modeli;

$Y_{t}=\phi_{0}+\phi_{1} Y_{t-1}+\phi_{2} Y_{t-2}+\ldots+\phi_{p} Y_{t-p}+\varepsilon_{t}-\theta_{1} \varepsilon_{t-1}-\theta_{2} \varepsilon_{t-2}-\ldots-\theta_{q} \varepsilon_{t-q}(1)$

şeklinde olmaktadır. Burada $Y_{t}$; d dereceden 
fark1 alınmış gözlem değerlerini, $\varepsilon_{t} ; \mathrm{t}$ zamandaki hata terimlerini, $\phi_{i}(i=1,2,3 \ldots p)$ ve $\theta_{j}(j=1,2,3 \ldots q)$; model parametrelerini, $p$ ve $q$ ise sırasılyla otogresif süreç (AR) ve hareketli ortalama (MA) değerlerini göstermektedir.

Günümüzde durağanlığın saptanmasında farklı yöntemler kullanılmakta olup, en yaygın kullanılanlardan birisi ADF birim kök testidir. Dickey ve Fuller $(1979 ;$ 1981) tarafından ele alınan bu testte sabitsiz, sabitli ve trendli bir süreç izlenmekte ve buna göre seri trendli bir süreçte durağan hâle gelmişse, diğer süreçler izlenmeksizin bu değer esas alınmaktadır. Seri durağan hâle gelmemişse, sabit terimli, bunda da durağanlık sağlanamamışsa, sabit terimsiz sınama yapılır ve bu süreç sonucunda seriyi durağan hâle getiren değer baz alınır (Enders, 1995). ADF testi aşağıdaki eşitlikleri kapsamaktadır.

$$
\begin{aligned}
& \Delta Y_{t}=\delta Y_{t-1}+\sum_{j=1}^{p} \delta_{i} \Delta Y_{t-j}+\varepsilon_{t} \\
& \Delta Y_{t}=\mu+\delta Y_{t-1}+\sum_{j=1}^{p} \delta_{i} \Delta Y_{t-j}+\varepsilon_{t} \\
& \Delta Y_{t}=\mu+\beta t+\delta Y_{t-1}+\sum_{j=1}^{p} \delta_{i} \Delta Y_{t-j}+\varepsilon_{t}
\end{aligned}
$$

Birim kök testi için kurulan hipotezler ise şu şekildedir;

$H_{0}: \delta=0$ (Birim kök vardır, yani zaman serisi durağan değildir).

$H_{1}: \delta<0$ (Seri birim kök içermemektedir, durağandir).

Denklemlerde yer alan $(\Delta)$ birinci fark işlemcisini,

\begin{tabular}{cccc}
\hline $\begin{array}{c}\text { Logaritmik verilere ait } \\
\text { testler }\end{array}$ & t-istatistiği & $\begin{array}{c}\text { Önem } \\
\text { derecesi }\end{array}$ \\
\hline $\begin{array}{c}\text { Artırılmış Dickey-Fuller } \\
\text { testleri }\end{array}$ & 1,088317 & 0,9242 \\
\hline & $\% 1$ & $-2,641672$ & \\
$\begin{array}{c}\text { Test kritik } \\
\text { değerleri }\end{array}$ & $\% 5$ & -1.952066 & \\
& $\% 10$ & $-1,610400$ & \\
\hline
\end{tabular}

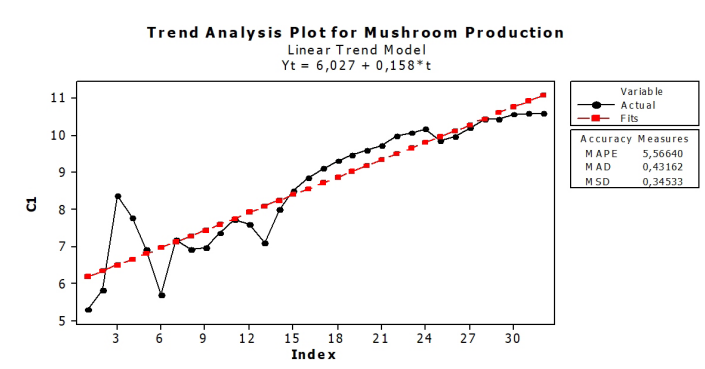

a.Durağan olmayan ADF testi ve Trend analizi grafikleri
$\left(Y_{t}\right) t$ dönemde kullanılan zaman serisini, $(\mu)$ sabit terimi, $(\beta \mathrm{t})$ zaman trendini, $\left(\varepsilon_{\mathrm{t}}\right)$ hata terimini, $(\mathrm{p})$ gecikme uzunluğunu göstermektedir (Sevüktekin ve Nargeleçekenler, 2010; Kılıç, 2015).

\section{Bulgular}

\subsection{ADF birim kök testleri}

Türkiye mantar üretim değerlerine ait ADF test sonuçlarına bakıldığında (Şekil 1a) test istatistiği 1,0883617, kritik değerlerden büyük olduğu için serinin birim kök içerdiği görülmektedir. Yine önem derecesinin 0,9242>0,05 olması serinin durağan olmadığını göstermektedir. Ayrıca artan trend analizi değerleri de serinin mevsimsel faktörün etkisinde olduğunu göstermektedir. $\mathrm{Bu}$ nedenle mantar üretim değerleri tahmin işleminden önce farkları alınarak durağan hâle getirilmiştir. 2. derece farkları alındıktan sonra durağan hâle gelen mantar üretim değerlerine ait ADF test sonuçlar1 ve trend analizi grafiği Şekil 1b'de verilmiştir. Grafik incelendiğinde test istatistiği -7,052710'un kritik değerlerden küçük olduğu ve serinin birim kök içermediği görülmektedir. Yine önem derecesi $0,000<0,05$ 'ten küçük olması ve trendin ortadan kalkması, serinin durağanlaştığını ve ARIMA ile tahmin için kullanılabileceğini göstermektedir.

\subsection{ARIMA (Box-jenkins) modeli ve tahmin}

Veriler durağan hâle getirildikten sonra en uygun ARIMA modelleri araştırılmış ve en iyi istatistiksel sonuç, ARIMA $(2,2,2)$, ARIMA $(2,2,3)$ ve ARIMA $(3,2,1)$ modellerinde elde edilmiştir. Bu modellerden ARIMA $(3,2,1)$, daha anlamlı değerlere ve daha iyi öngörü performansına sahip oldu-

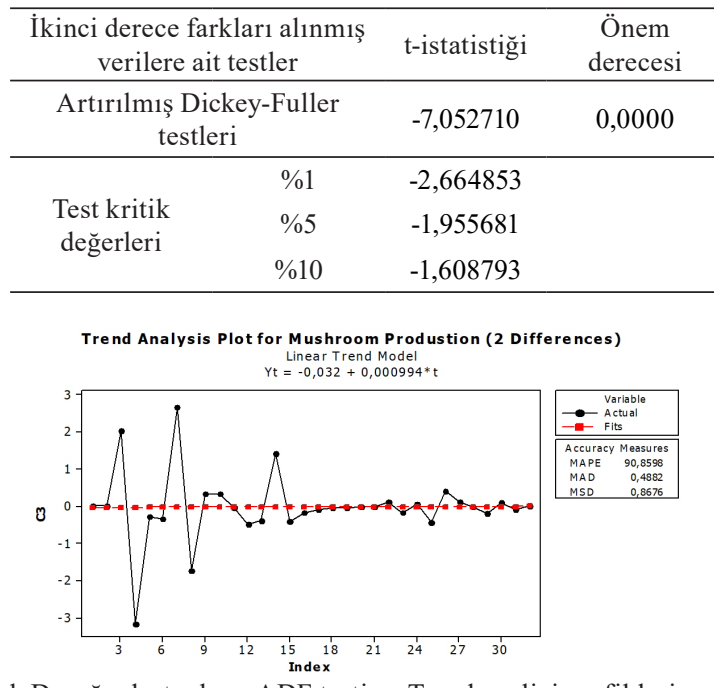

b.Durağanlaştırılmış ADF testi ve Trend analizi grafikleri

Şekil 1. Mantar üretim değerlerine ait ADF test sonuçları ve trend analizi grafikleri Figure 1. ADF test results and trend analysis graphs of mushroom production values 
ğu için tahmin amacıyla kullanılmıştır. Tablo 2'de ARIMA $(3,2,1)$ modeline ait istatistik sonuçlarının yer aldığı program çıktıları görülmektedir. Tablo 2 incelendiğinde modelin $0,05(\mathrm{p}<0,05)$ önem düzeyinde anlamlı olduğu görülmektedir. Hata Kareleri Ortalaması (MSE): 0,27557, oldukça düşük bir değer olarak elde edilmiştir. Yine Ljuing box ki-kare istatistiklerine bakıldı ğında da modelin $\% 5(\mathrm{p}>0,05)$ önem derecesinde anlamlı ve yeterli olduğu söylenebilir. Yani model tahmin için kullanılabilir.

Tablo 2. ARIMA $(3,2,1)$ modeline ilişkin istatistik sonuçlar

Table 2. Statistical results for ARIMA $(3,2,1)$ model

\begin{tabular}{|c|c|c|c|c|c|}
\hline Tip & Katsayilar & Standart hata & $\mathrm{T}$ & $\mathrm{P}$ (Önem derecesi) & \\
\hline AR 1 & $-0,3218$ & 0,1575 & $-2,04$ & 0,052 & \\
\hline AR 2 & $-0,5240$ & 0,1400 & $-3,74$ & 0,001 & \\
\hline AR 3 & $-0,7507$ & 0,1379 & $-5,44$ & 0,000 & \\
\hline MA 1 & 0,9630 & 0,0855 & 11,26 & 0,000 & \\
\hline Constant & $-0,00371$ & 0,004766 & $-0,78$ & 0,443 & \\
\hline Fark alma & 2 & $\begin{array}{c}\text { Gözlem sayısı } \\
\text { (orijinal seri) }\end{array}$ & 32 & $\begin{array}{c}\text { Gözlem sayısı } \\
\text { (fark alma işleminden sonra) }\end{array}$ & 30 \\
\hline $\begin{array}{c}\mathrm{SD} \\
\text { (Serbeslik derecesi) }\end{array}$ & 25 & $\begin{array}{c}\text { MSE } \\
\text { (Hata kareleri ortalaması) }\end{array}$ & 0,27557 & $\begin{array}{c}\mathrm{SS} \\
\text { (Hata kareleri toplamı) }\end{array}$ & 6,88914 \\
\hline \multicolumn{6}{|c|}{ Box-pierce (Ljuing box) ki-kare istatistikleri } \\
\hline Lag (Gecikme) & 12 & 24 & 36 & 48 & \\
\hline Ki-kare & 14,5 & 17,7 & - & - & \\
\hline $\mathrm{SD}$ & 7 & 19 & - & - & \\
\hline P-Değeri & 0,043 & 0,546 & - & - & \\
\hline
\end{tabular}

Şekil 2'de ARIMA $(3,2,1)$ modeline ait mantar üretimi tahmin sonuçları verilmiştir. Sonuçlara genel olarak bakıldığında, mantar üretiminin 2017 yılında 47,5 bin tona, 2020 y1lında 63,6 bin tona, 2026 yılında ise 108,7 bin tona ulaşacağı öngörülmüştür.

\section{Sonuç ve Öneriler}

Çalışmada 1985-2016 yılları arasındaki Türkiye mantar üretim verilerinden yola çıkılarak gelecek on yıllık mantar üretim değerleri ARIMA (Box-

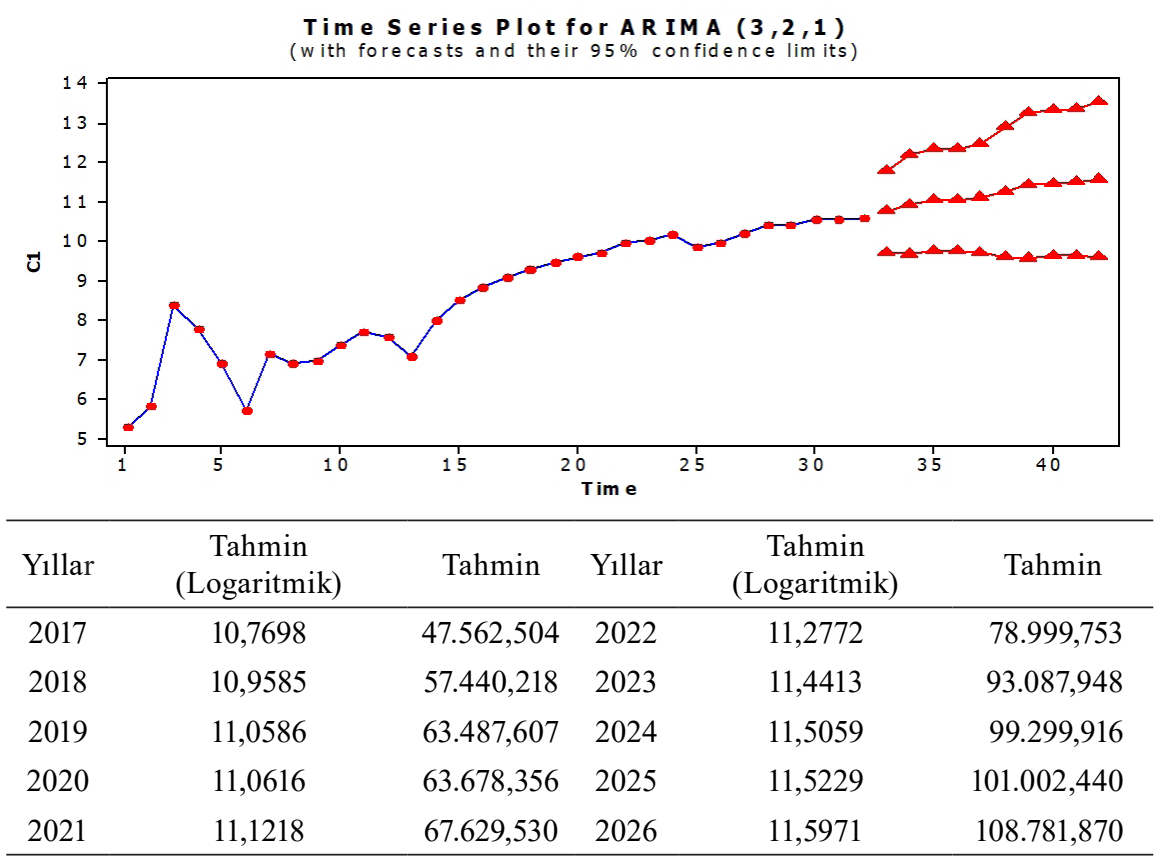

Şekil 2. Mantar üretimi tahmin sonuçları

Figure 2. Mushroom production forecast results 
Jenkins) yöntemi kullanılarak tahmin edilmiştir. Sonuçlar mantar üretiminin kademeli bir şekilde artarak 2025 yılında 100 bin tonu aşacağını göstermiştir. Tahmin sonuçları özellikle mantar üretici sayısındaki artış, devletin son yıllarda genç girişimciler için vermiş olduğu destekler ve destek miktarlarındaki artış, kolay kompost temini ve kompost hazırlayan firmaların giderek çoğalmas1, mantarın besleyici özellikleri ve faydaları konusundaki bilinçlenme gibi olumlu durumlar göz önüne alındığında oldukça tutarlı bulunmuştur.

Türkiye, özellikle zengin biyoçeşitlilik ve farklı iklim türlerine sahip bölgeler bulunması bakımından mantar üretimini arttırabilecek bir potansiyele sahiptir. Bu kapsamda farklı türde ve ticari değeri yüksek mantar türlerinin kültüre alınması için çalışmalar arttırılmalı, kültür mantarı üretimi için bölgesel teşvikler getirilmeli ve mantar üretimiyle ilgili kurslar, seminerler düzenlenmelidir.

Üretimin daha fazla artması, mantarın tüketiciler tarafindan daha fazla tüketilen besin alternatifi olarak tercih edilmesinden geçmektedir. Tüketicileri bu konuda bilinçlendirmek amacıyla üretici, üniversite ve sanayi işbirliğine gidilmeli; mantarın besin değerleri, faydaları hakkında tanıtımlar için yerel basin ve medyadan yararlanılmalı; gerekirse kurutma, konserve gibi farklı tüketim alternatifleri geliştirilmelidir.

\section{Kaynaklar}

Boa, E., 2004. Wild Edible Fungi A Global Overview of Their Use and Importance to People. NonWood Forest Products 17, Fao Press, Rome-Italy.

Box, G.E.P., Jenkins, G.M., 1970. Time Series Analysis: Forecasting and Control. Holden-Day Inc., San Francisco, California.

Dickey, D.A., Fuller W.A., 1979. Distribution of the estimators for autoregressive time series with a unit root. Journal of the American Statistical Association, 74: 427-431.

Dickey, D.A., Fuller, W.A., 1981. Likelihood ratio statistics for autoregressive time series with a unit root. Econometrica 49 (4): 1057-1072.

Enders, W., 1995. Applied Econometris Time Series. John Wiley \& Sons, New York.

Eren, E., Pekşen, A., 2014. Türkiye'de kültür mantarı üretimi, sorunları ve çözüm yolları. I. Ulusal
Mikoloji Günleri, Erzurum, 01-04 Eylül 2014, s. 29.

Erkel, I., 1992. Dünya'da ve Türkiye'de kültür mantarcılığının durumu. Türkiye 4. Yemeklik Mantar Kongresi, Yalova, 1: 1-8.

FAO, 2018. Food and Agriculture Organization of the United Nations. Website, http://www.fao.org/ faostat/, Accessed: 01.05.2018.

Hamzaçebi, C., Kutay, F., 2004. Yapay sinir ağları ile Türkiye elektrik enerjisi tüketiminin 2010 yıl1na kadar tahmini. Gazi Üniversitesi MühendislikMimarlık Fakültesi Dergisi, 19 (3): 227-233.

Kılıç, C., 2015. Tüketici kredileri ve cari açık arasındaki ilişki: Türkiye örneği. Atatürk Üniversitesi Iktisadi ve İdari Bilimler Dergisi, 29 (2): 407-420.

Kibar, B., 2015. Iğdır ili mantar tüketim alışkanlıklarının belirlenmesi. Iğdır Üniversitesi Fen Bilimleri Enstitüsü Dergisi, 5 (4): 9-16.

Kurt, R., Can, A., Sivrikaya, H., 2018a. Bartın ilinde kültür mantarı yetiştiriciliğinin mevcut durumu, sorunları ve bazı çözüm önerileri. Journal of Bartin Faculty of Forestry, 20 (2): 25-33.

Kurt, R., Imren, E., Cabuk, Y., Karayilmazlar, S., 2018b. Estimation of global wood pellet production as a renewable energy source by ARIMA method. Fresenius Environmental Bulletin, 27 (7): 5147-5152.

Özdemir, M.A., Bahadır, M., 2010. Denizli'de Box Jenkins tekniği ile küresel iklim değişikliği öngörüleri. The Journal of International Social Research, 3 (12): 352-362.

Sevüktekin, M., Nargeleçekenler, M., 2010. Ekonometrik Zaman Serileri Analizi: Eviews Uygulamalı. Geliştirilmiş 3. Baskı, Nobel Yayın Dağıtım, Ankara, $494 \mathrm{~s}$.

Şen, S., Yalçın, M., 2010. Dünya ve Türkiye'de kültür mantarcılığı ve geliştirilmesi. III. Ulusal Karadeniz Ormancılık Kongresi, 20-22 May1s 2010, (3): 1208-1216.

Topçuoğlu, K., Pamuk, G., Özgürel, M., 2005. Gediz havzası yağışlarının stokastik modellemesi. Ege Üniv. Ziraat. Fak. Derg., 42: 89-97.

TÜİK, 2018. Türkiye İstatistik Kurumu. Ankara, www.tuik.gov.tr, Ziyaret tarihi: 05.05.2018. 